\title{
Highly efficient emission and high-CRI warm white light-emitting diodes from ligand-modified $\mathrm{CsPbBr}_{3}$ quantum dots
}

\author{
Dongdong Yan ${ }^{1 \dagger}$, Shuangyi Zhao ${ }^{1 \dagger}$, Yubo Zhang ${ }^{2}$, Huaxin Wang ${ }^{1}$ and \\ Zhigang Zang ${ }^{1 *}$
}

\begin{abstract}
All-inorganic $\mathrm{CsPbBr}_{3}$ perovskite quantum dots (QDs) have received great attention in white light emission because of their outstanding properties. However, their practical application is hindered by poor stability. Herein, we propose a simple strategy to synthesize excellent stability and efficient emission of $\mathrm{CsPbBr}_{3} \mathrm{QDs}$ by using 2-hexyldecanoic acid (DA) as a ligand to replace the regular oleic acid (OA) ligand. Thanks to the strong binding energy between DA ligand and QDs, the modified QDs not only show a high photoluminescence quantum yield (PLQY) of 96\% but also exhibit high stability against ethanol and water. Thereby warm white light-emitting diodes (WLEDs) are constructed by combining ligand modified $\mathrm{CsPbBr}_{3}$ QDs with red AglnZnS QDs on blue emitting InGaN chips, exhibiting a color rendering index of 93, a power efficiency of $64.8 \mathrm{Im} / \mathrm{W}$, a CIE coordinate of $(0.44,0.42)$ and correlated color temperature value of $3018 \mathrm{~K}$. In addition, WLEDs based on ligand modified $\mathrm{CsPbBr}_{3} \mathrm{QDs}$ also exhibit better thermal performance than that of WLEDs based on the regular $\mathrm{CsPbBr}_{3}$ QDs. The combination of improved efficiency and better thermal stability with high color quality indicates that the modified $\mathrm{CsPbBr}_{3}$ QDs are ideal for WLEDs application.
\end{abstract}

Keywords: $\mathrm{CsPbBr}_{3}$ quantum dots; ligand modification; stability; efficiency; white light-emitting diodes

Yan DD, Zhao SY, Zhang YB, Wang HX, Zang ZG. Highly efficient emission and high-CRI warm white light-emitting diodes from ligandmodified $\mathrm{CsPbBr}_{3}$ quantum dots. Opto-Electron Adv 5, 200075 (2022).

\section{Introduction}

Nowadays, lighting accounts for approximately one-fifth of the global electricity consumption ${ }^{1}$, which leads to a large increase in the emissions of carbon dioxide $\left(\mathrm{CO}_{2}\right)^{2}$. To reduce the energy demand for lighting, solid-state white light-emitting diodes (WLEDs) are becoming the most promising illumination sources, which are much more efficient, energy saving and environmental friendly than that of the traditional bulbs and fluorescent lighting sources ${ }^{3-6}$. A common way of achieving a white light emission is composed of a near-UV or blue LEDs with a coating of either down-conversion materials (i.e. YAG:Ce ${ }^{3+}$ phosphors) or a combination of red and green phosphors ${ }^{7,8}$. Unfortunately, such WLEDs suffer from poor white light performance after extensive use due to the different degradation rates between the blue LEDs and phosphors. In addition, they usually exhibit unsatisfactory high correlated color temperature (CCT) value and a low color rendering index $(\mathrm{CRI}<80)$ due to the facile absence of the red or green emission. In principle, an

${ }^{1}$ Key Laboratory of Optoelectronic Technology \& Systems (Ministry of Education), Chongqing University, Chongqing 400044, China; ${ }^{2}$ Department of Physics, Southern University of Science and Technology, Shenzhen 518055, China.

tThese authors contributed equally to this work.

*Correspondence: ZG Zang, E-mail: zangzg@cqu.edu.cn

Received: 30 August 2020; Accepted: 20 February 2021; Published online: 25 January 2022

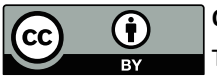

Open Access This article is licensed under a Creative Commons Attribution 4.0 International License.

To view a copy of this license, visit http://creativecommons.org/licenses/by/4.0/.

(C) The Author(s) 2022. Published by Institute of Optics and Electronics, Chinese Academy of Sciences. 
ideal white light emitting system needs the light source with an appropriate CCT between $2500 \mathrm{~K}$ and $6500 \mathrm{~K}$, and CRI above $80^{9,10}$. In order to achieve high performance WLEDs, developing a highly efficient red and green quantum dots (QDs) for high CRI value of warm WLEDs is a very attractive strategy.

Recently, all-inorganic perovskite quantum dots (QDs) $\mathrm{CsPbX}_{3}(X=\mathrm{Cl}, \mathrm{Br}$, I) have rapidly advanced the optoelectronic fields owing to their remarkable optical performance, such as high photoluminescence quantum yield (PLQY), narrow emission bandwidths and tunable wavelength $^{11-13}$. Because of these superior properties, $\mathrm{CsPbX}_{3}$ QDs can be elaborately designed for a series of optoelectronic devices including solar cells, photodetectors, lasers and light-emitting diodes ${ }^{14-18}$. In particular, owing to the nature of their facile color tunability and sharp emission, such unique characteristics enable the luminescence $\mathrm{CsPbX}_{3}$ QDs to be very promising emitting materials for LEDs ${ }^{19}$. For example, Zeng's group first reported the blue, green and yellow LEDs based on the $\mathrm{CsPbX}_{3} \mathrm{QDs}^{20}$. Li et al. and Ling et al. have both reported their LEDs based on $\mathrm{CsPbBr}_{3}$ QDs with about 6\% $\mathrm{EQE}^{21,22}$. Up to now, many strategies have been taken to achieve high efficiency perovskite LEDs, including the compositional engineering, utilizing surface engineering and dimensional engineering ${ }^{21,23-29}$. In addition, based on the green $\mathrm{CsPbBr}_{3}$ QDs, it is possible to realize the high quality warm WLEDs because of their color purity and color gamut. For example, Song and co-workers realize a highly efficient white light generation in LEDs using $\mathrm{CsPBr}_{3}$ QDs with red phosphor on InGaN blue chip ${ }^{30}$. Chen et al. designed $\mathrm{CsPbBr}_{3}$ QDs/PMMA composites and obtained a WLEDs with a CRI of $89.2^{31}$. Regardless of the rapid progress in WLEDs using perovskite QDs, $\mathrm{CsPbBr}_{3}$ QDs still suffer from problems related to poor humidity and poor thermal stability, which restrict the development of high performance WLEDs ${ }^{32,33}$. The poor stability of $\mathrm{CsPbBr}_{3}$ QDs is mainly related to the surface defect, surface long ligands and ionic migration behavior $^{34-36}$. For example, QD dissolution may occur under the surrounding of polar solvents or thermal conditions, resulting in poor stability and luminescence ${ }^{37-39}$. To improve the stability of $\mathrm{CsPbBr}_{3}$ QDs, a variety of strategies have been developed, including coating an inert material, surface treatment and doping/alloying heteroatoms $\mathrm{s}^{40-44}$. In fact, among those different methods in improving the stability of $\mathrm{CsPbBr}_{3}$ QDs, ligand modification is a very simple and effective approach ${ }^{37,45}$. During the initial stages of ligand research for $\mathrm{CsPbBr}_{3}$ QDs, most ligands were used for the enhancement of surface coverages and suppression of surface defects of QDs ${ }^{46}$. However, these ligands on the surface of QDs are very labile. Specifically, they are readily desorbed during the purification process resulting in incomplete surface passivation and poor luminescence efficiency. The main reason for this problem is the poor binding energy between the ligand and QDs. Recently, the most ideal ligands that bind more strongly to the surface can improve luminescence and stability of $\mathrm{CsPbBr}_{3}$ QDs, such as propanesulfonate and alkyl phosphonic $\operatorname{acids}^{37,47}$. In other words, the effective ligand modification strategy of $\mathrm{CsPBr}_{3}$ QDs is fundamental to synthesize high quality QD with excellent optical properties, enhancing the stability and improving device performance.

In addition, it is worth pointing out that the full-width at half-maximum (FWHM) of the red-emitting component is a very important factor for realizing high performance WLEDs ${ }^{48-51}$. In terms of the optionally red-emission materials for the WLEDs, the red-emission $\mathrm{CsPbI}_{3}$ perovskite QDs suffer from poor stability and narrow FWHM of the emission spectrum ${ }^{52,53}$. Particularly, the perovskite phases of red $\mathrm{CsPbI}_{3}$ QDs have been demonstrated to be metastable under ambient conditions and they easily undergo a phase transition resulting in diminishing their optical properties ${ }^{54-56}$. Consequently, for obtaining the high performance warm WLEDs, the redemission AgInZnS QDs with a wide FWHM of $90 \mathrm{~nm}$ is suitable and chosen to act as the red component for the warm light emission ${ }^{57,58}$.

In this work, we present a facile strategy to achieve excellent stability of $\mathrm{CsPbr}_{3}$ QDs and high performance of WLEDs by using shorter 2-hexyldecanoic acid (DA) ligand to replace $\mathrm{OA}$ ligand for $\mathrm{CsPbBr}_{3}$ QDs. The ligand modified $\mathrm{CsPbr}_{3}$ QDs exhibit a high PLQY of 96\% with significantly enhanced stability, even when exposed to ethanol and water environments. Consequently, WLEDs by combining a blue InGaN LED with green ligand modified $\mathrm{CsPbBr}_{3}$ QDs and red AgInZnS QDs are achieved, which generate high quality warm white light emission with a power efficiency of $64.8 \mathrm{~lm} / \mathrm{W}$, CRI of 93 , color coordinate of $(0.44,0.42)$, and correlated color temperature (CCT) of $3018 \mathrm{~K}$. In particular, the WLEDs based on the modified $\mathrm{CsPBr}_{3}$ QDs show a good thermal performance under high driving current, verifying their potential application in the field of solid-state lighting. 


\section{Experimental}

\section{Chemicals and reagents}

Lead bromide $\left(\mathrm{PbBr}_{2}, 99.9 \%\right)$ and Cesium carbonate $\left(\mathrm{Cs}_{2} \mathrm{CO}_{3}, 99.9 \%\right)$ were purchased from Xi'an polymer Light Technology Corp. Octadecene (ODE, > 90\%, Adamas), OA ( $>90 \%$, Adamas), DA ( $>98 \%$, TCI), OAm (>90\%, Aladdin). Silver nitrate $\left(\mathrm{AgNO}_{3}, 99.8 \%\right.$, Aldrich), zinc stearate $\left(\mathrm{Zn}(\mathrm{St})_{2}, 90 \%\right.$, Aldrich), indium acetate (In(Ac) 3, 99.99\%, Aldrich), n-dodecylthiol (DDT, 99.8\%, Aladdin), sulfur (S, 99.99\%, Aldrich). All these reagents were used without further purification.

\section{Preparation and characterization of materials}

\section{Synthesis of $\mathrm{CsPbBr}_{3}-\mathrm{OA}$ QDs}

$4 \mathrm{~mL}$ of ODE, $0.5 \mathrm{~mL}$ of $\mathrm{OA}$ and $\mathrm{Cs}_{2} \mathrm{CO}_{3}(81.5 \mathrm{mg})$ were loaded into a $100 \mathrm{~mL}$ three-neck flask $1, \mathrm{PbBr}_{2}(0.188$ $\mathrm{mmol}$ ) and $5 \mathrm{~mL}$ of ODE were loaded into another $100 \mathrm{~mL}$ three-neck flask 2. Both the two flasks were degassed under vacuum and nitrogen flow and then heated to $120^{\circ} \mathrm{C}$. After $1 \mathrm{~h}, 0.5 \mathrm{~mL}$ of OAm and $0.5 \mathrm{~mL}$ of OA were quickly injected into flask 2 , and then the temperature was raised to $150{ }^{\circ} \mathrm{C}$ to ensure complete dissolution. Keep the mixture at $150{ }^{\circ} \mathrm{C}$ about 2 min and then Csoleate solution $(0.4 \mathrm{~mL}$ in $\mathrm{ODE})$ was quickly injected. After $5 \mathrm{~s}$, the solution turned green immediately and the reaction mixture was cooled by the ice-water bath to room temperature.

\section{Synthesis of $\mathrm{CsPbBr}_{3}$-DA QDs}

$4 \mathrm{~mL}$ of ODE, $0.5 \mathrm{~mL}$ of DA and $\mathrm{Cs}_{2} \mathrm{CO}_{3}(81.5 \mathrm{mg})$ were loaded into $100 \mathrm{~mL}$ three-neck flask $1, \mathrm{PbBr}_{2}(0.188$ $\mathrm{mmol})$, ODE $(5 \mathrm{~mL}), \mathrm{OAm}(0.5 \mathrm{~mL})$ and DA $(0.5 \mathrm{~mL})$ were loaded into another $100 \mathrm{~mL}$ three-neck flask 2 . Both the two flasks were degassed under vacuum and nitrogen flow and heated to $120^{\circ} \mathrm{C}$ in $1 \mathrm{~h}$ under nitrogen flow. Temperature was set up to $150{ }^{\circ} \mathrm{C}$ to ensure complete dissolution, keeping the mixture at $150{ }^{\circ} \mathrm{C}$ for $2 \mathrm{~min}$ and then Cs-oleate solution $(0.4 \mathrm{~mL}$ in ODE) was quickly injected. After $5 \mathrm{~s}$, the solution turned green immediately and the reaction mixture was cooled by the ice-water bath to room temperature.

\section{Synthesis of AgInZnS QDs}

$\mathrm{In}(\mathrm{Ac})_{3}(0.4 \mathrm{mmol})$ and $\mathrm{AgNO}_{3}(0.1 \mathrm{mmol})$ were added in ODE $(4 \mathrm{~mL}), \mathrm{OA}(0.2 \mathrm{~mL})$ and $\mathrm{n}$-dodecylthiol $(0.75 \mathrm{~mL})$ in a $50 \mathrm{~mL}$ three-neck flask 1 , followed by the solution was heated to $60^{\circ} \mathrm{C}$ under nitrogen flow. Mean- while, the sulfur $(0.5 \mathrm{mmol})$ was dissolved in OAm $(0.5 \mathrm{~mL})$ and ODE $(0.5 \mathrm{~mL})$ solution in bottle 1 . The $\mathrm{Zn}(\mathrm{St})_{2}(0.5 \mathrm{mmol})$ was dissolved in $\mathrm{OAm}(0.5 \mathrm{~mL})$ and ODE $(0.5 \mathrm{~mL})$ solution in bottle 2. After $30 \mathrm{~min}$, the mixture solution was heated to $90{ }^{\circ} \mathrm{C}$ for $10 \mathrm{~min}$. The sulfur solution (total solution in bottle 1) was quickly injected into the flask 1 . Then flask 1 was set up to $115^{\circ} \mathrm{C}$, subsequently, the $\mathrm{Zn}(\mathrm{St})_{2}$ solution (total in the bottle 2) was slowly injected. The reaction solution was kept at $115^{\circ} \mathrm{C}$ for $35 \mathrm{~min}$ for the formation of AgInZnS QDs. The crude reaction solution was centrifuged at $9500 \mathrm{rpm}$ for $10 \mathrm{~min}$ after adding some toluene. The obtained supernatant was added in ethanol solvents (according to 1:3 by volume) and precipitated again, the supernatant was discarded and obtained the purified AgInZnS QDs. The AgInZnS were eventually dispersed in $n$-hexane.

\section{Preparation of materials}

\section{Purification of $\mathrm{CsPbBr}_{3}$ QDs}

The crude solution was evenly split into two centrifuge tubes and the equal volume of $n$-butanol was added to each tube. The above mixture solution was centrifuged at $9000 \mathrm{rpm}$ for $5 \mathrm{~min}$. After centrifugation, the supernatant was discarded. Then, the precipitate was washed with toluene to remove large particles and agglomerates.

\section{Fabrication of $\mathrm{CsPbBr}_{3}$ QDs films}

The $\mathrm{CsPbBr}_{3}$ QDs films were fabricated onto the glass substrates by drop-coating the QDs solution under ambient conditions.

\section{Characterization of materials}

The XRD patterns were collected using monochromatized $\mathrm{Cu}$ Ka radiation (XRD-6100, SHIMADZU, Japan). The TEM images were obtained on an electron microscope (Libra 200 FE, Zeiss, Germany). Absorption spectra were adopted recorded on a UV-vis spectrophotometer (UV -vis: UV-2100, SHIMADZU, Japan). The photoluminescence spectroscopy was performed using a fluorescence spectrophotometer (PL: Agilent Cary Eclipse, Australia). The FTIR analysis (KBr pellet method) was performed with a Nicolet iS50 FT-IR Spectrometer (Thermo Fisher Scientific, Waltham, MA, USA) to characterize the product structure of EJTLE. The AFM images were recorded by an atomic force microscope (Asylum Research, MFP-3D-BIO, USA). All NMR spectra were collected on a Bruker $400 \mathrm{M}$ system. The XPS 
analysis was carried out using an Escalab $250 \mathrm{Xi}$ system. The performances of the fabricated WLEDs were measured using a spectrograph of PR670 with an analyzer system.

\section{Fabrication of white LED devices}

Typically, the polymethyl-methacrylate (PMMA, $15 \mathrm{mg}$ ) and $\mathrm{CsPbBr}_{3}$ QDs (25 mg) were dissolved in $20 \mathrm{~mL}$ toluene and stirred for $24 \mathrm{~h}$. Similarly, PMMA (15 mg) and AgInZnS QDs (30 mg) were all dissolved in $20 \mathrm{~mL}$ toluene and stirred for $24 \mathrm{~h}$. To fabricate WLEDs, the above obtained two mixture solution were successively dropped on a blue InGaN chip. The fabricated WLED was annealed at $40{ }^{\circ} \mathrm{C}$ for $30 \mathrm{~min}$ in the ambient.

\section{Computational details}

The density functional theory calculations are performed using the FHI-aims code ${ }^{59}$. We use the generalized-gradient-approximation (GGA) exchange-correlation functional in the form of Perdew-Burke-Ernzerhof $(\mathrm{PBE})^{60}$. The long-range van der Waals interaction is considered using the Tkatchenko-Scheffler correction ${ }^{61}$.

\section{Results and discussion}

Figure $1(\mathrm{a}-\mathrm{d})$ shows the surface models for simulating the OA/DA adsorption on the $\mathrm{CsPBr}_{3}$ surfaces. The surface models contain large vacuum spaces (i.e., $18 \AA$ and $\sim 45 \AA\left(1 \AA=10^{-10} \mathrm{~m}\right)$ within the planar directions and along with the vertical directions, respectively) to avoid the interaction between molecules and their im- ages. Whereas the bottom $\mathrm{CsPbBr}_{3}$ layer is fixed to their bulk structural parameters, the upper two $\mathrm{CsPbr}_{3}$ layers are fully relaxed to simulate the surface effects and also their bonding interactions with the molecules. The structure models are carefully relaxed since the numerical convergence could sensitively influence the validity of the calculated binding energies (see more details in the Supporting Information). Figure 1(e) shows the binding strengths of $\mathrm{OA} / \mathrm{DA}$ with $\mathrm{CsPbr}_{3}$ with four different adsorption models, which indicates that DA has a stronger binding ability than OA. We first consider $\mathrm{OA} / \mathrm{DA}$ adsorptions on the pristine CsBr-terminated surfaces (Fig. 1(a-b)), which is the most common termination surfaces of $\mathrm{CsPbBr}_{3}$ quantum $\operatorname{dots}^{62}$. The hydrogen atom from the $\mathrm{COOH}$ group is initially placed on top of a $\mathrm{Br}$ anion, since it was usually believed that the small molecules bind with the CsBr-surfaces through hydrogen bonding ${ }^{59,60}$. We then carefully relax the surface structure in order to find the most stable adsorption configurations. For the structure models of Fig. 1(a) and 1(b), our results (see Fig. 1(e)) indicate, strictly speaking, a stronger binding ability of DA $\left(E_{\text {binding }}=-0.136 \mathrm{eV}\right)$ than OA ( $E_{\text {binding }}=-0.127 \mathrm{eV}$ ). However, we point out that the binding energies from these models are quite small, which is understood from the below analysis of the bonding interactions between the molecules and $\mathrm{CsBr}$ surface. The distortion patterns of the $\mathrm{PbBr}_{6}$ octahedra around the adsorption sites (see the insets of Fig. 1(a) and $1(\mathrm{~b})$ ) clearly reveal, contrary to the previous understanding ${ }^{63,64}$, a mutual repulsion between $\mathrm{H}$ and $\mathrm{Br}$
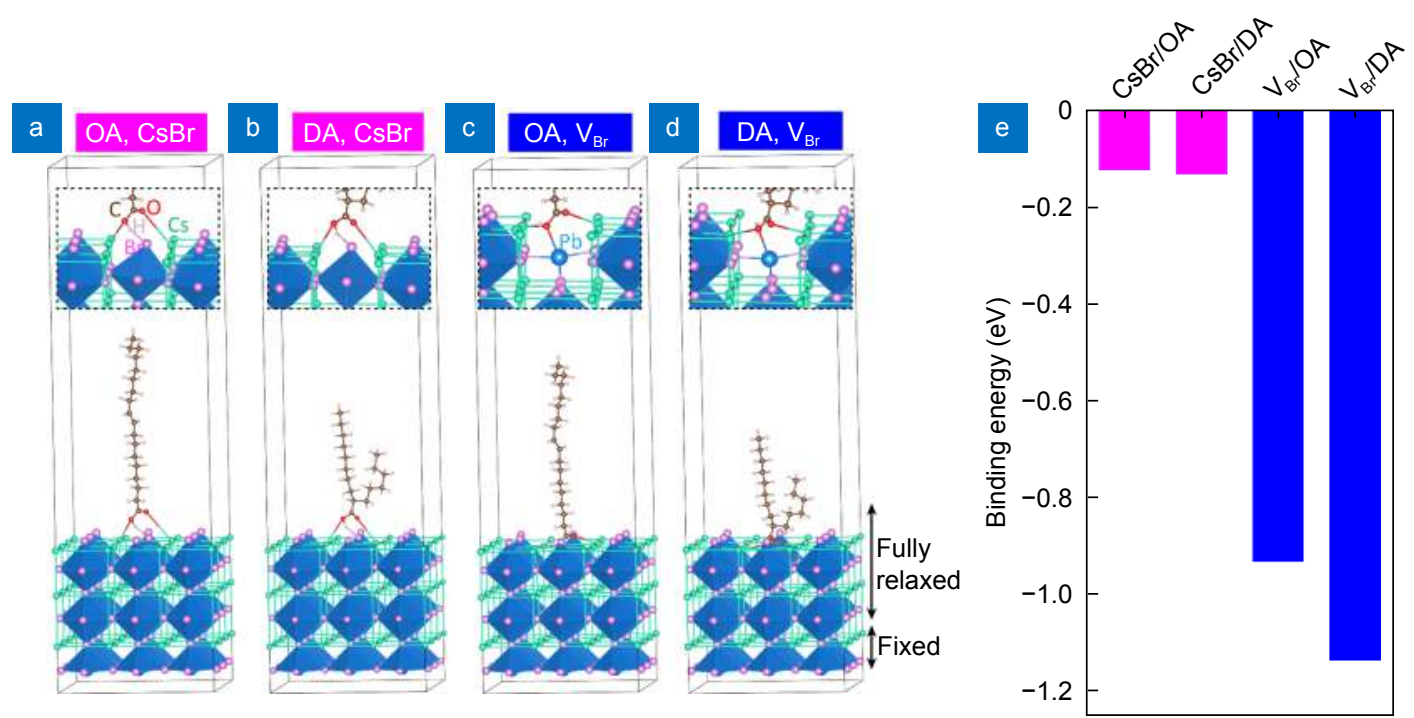

Fig. 1 | Relaxed surface models for simulating the adsorption of OA/DA molecules on the $\mathrm{CsPbBr}_{3}$ surface. The insets are the zoomedin plot of the bonded regions. (a) OA on top of the pristine CsBr-terminated surface. (b) DA on top of the pristine CsBr-terminated surface. (c) OA bonding with a Br-vacancy. (d) DA bonding with a Br-vacancy. (e) The binding energies of the four interfaces. 
atoms. Therefore, the $\mathrm{H}-\mathrm{Br}$ repulsion partially compensates the electrostatic attraction between the $\mathrm{O}$ anion and $\mathrm{Cs}$ cation (from the $\mathrm{COOH}$ group and the $\mathrm{CsBr}$ surfaces, respectively), resulting in weak binding energies.

Much stronger binding of both $\mathrm{OA}$ and DA molecules is found in the presence of Br-vacancies (see Fig. $1(\mathrm{c})$ and $1(\mathrm{~d})$ ), agreeing well with the previous report ${ }^{62}$. When constructing the structure models, one $\mathrm{Br}$ atom is removed from the $\mathrm{CsBr}$ surfaces, and the molecular $\mathrm{H}$ atom is initially placed on top of the exposed $\mathrm{Pb}$ atom. Structural relaxations (of the Fig. 1(c) and 1(d) models) move the $\mathrm{H}$ atom (in the $\mathrm{COOH}$ group) toward void spaces created by the Br-vacancy, which effectively avoids the $\mathrm{H}$-derived repulsion interactions as discussed earlier. The local bond networks (see the insets of Fig. $1(c)$ and $1(d)$ ) show the bonding of one $\mathrm{O}-\mathrm{Pb}$ pair and two O-Cs pairs. Therefore, it is not surprising that both $\mathrm{DA}$ and $\mathrm{OA}$ have much strong binding energies on these Br-defective surfaces $\left(E_{\text {binding }}=-0.933\right.$ and $-1.135 \mathrm{eV}$ for the OA and DA adsorption structures, respectively). Moreover, as shown in Fig. 1(e), the binding of a DA ligand with the $\mathrm{CsPbBr}_{3}$ QDs is clearly more stable, i.e., $\Delta E=0.202 \mathrm{eV}$, than that of an OA ligand.

To confirm our calculation results, the pristine $\mathrm{CsPb}$ $\mathrm{Br}_{3}$-OA QDs were synthesized via the conventional hotinjection method using lead bromide and cesium oleate as precursors. However, the $\mathrm{Cs}_{\mathrm{PbBr}}$-DA QDs were synthesized using a modified hot-injection method. The synthesis process of the modified $\mathrm{CsPbBr}_{3}$ QDs by using 2-hexyldecanoic acid (DA) as a ligand to replace the regular oleic acid (OA) ligand is schematically shown in Fig. 2(a), and the detailed synthesis process could be found in our experimental section. As shown in Fig. 2(a), OA ligand is composed of the long carbon chain, while DA ligand is composed of two short branched chains. The previous reports have been demonstrated that using short ligands to replace the regular long ligands is an effective strategy to enhance the stability of QDs ${ }^{62,65-69}$. These former reports inspired us to choose the DA ligands with two short branched chains for the synthesis of $\mathrm{CsPbrr}_{3}$ QDs. Besides, it is a reasonable hypothesis that DA ligand with the two short branched chains may increase the binding energy between QDs and the ligand, resulting in significantly enhanced stability of QDs. Figure 2(b) shows the photographs of the synthesized CsPb$\mathrm{Br}_{3}$ QD solutions under daylight (left) and UV light excitation (right). In comparison with the $\mathrm{CsPbBr}_{3}-\mathrm{OA}$ QDs solution, the $\mathrm{CsPbBr}_{3}$-DA QDs solution exhibit bet- ter clarification under daylight and brighter green luminescence under the UV lamp (365 nm). The measured PLQY of $\mathrm{CsPbBr}_{3}-\mathrm{OA}$ QDs is only $84 \%$, while the PLQY of $\mathrm{CsPbBr}_{3}-\mathrm{DA}$ QDs is $96 \%$. Figure 2(c) shows the highresolution transmission electron microscopy (HRTEM) images of the $\mathrm{CsPbBr}_{3}$-OA QDs and $\mathrm{CsPbBr}_{3}-\mathrm{DA}$ QDs in which the cubic structure and the lattice fringes of $0.58 \mathrm{~nm}$ for both QDs are clearly demonstrated. Fig. S2 present the low-resolution TEM images of the two $\mathrm{CsPb}$ $\mathrm{Br}_{3}$ QDs. The elemental mapping results exhibit a uniform distribution of $\mathrm{Cs}, \mathrm{Pb}$, and $\mathrm{Br}$ atoms in the two $\mathrm{CsPBr}_{3}$ perovskite QDs (see Fig. S3). X-ray diffraction (XRD) data has further confirmed the phase purity and crystallinity of both $\mathrm{CsPbBr}$. perovskite QDs (see Fig. $2(\mathrm{~d}))$. The diffraction peaks at $2 \theta$ values of $15.2^{\circ}, 21.7^{\circ}$ and $30.7^{\circ}$, corresponding to (100), (110) and (200) facets of standard $\mathrm{CsPbBr}_{3}$ QDs, which indicate the high-quality cubic phase for two $\mathrm{CsPbBr}_{3}$ QDs. Obviously, the $\mathrm{XRD}$ results are agreed well with the HRTEM images. As described in Fig. S4(a-d), the X-ray photoelectron spectroscopy (XPS) has been recorded to investigate the chemical composite of the two $\mathrm{CsPbBr}_{3}$ QDs. The peaks originating from $\mathrm{Cs} 3 \mathrm{~d}, \mathrm{~Pb} 4 \mathrm{f}$ and $\mathrm{Br} 3 \mathrm{~d}$ electrons have been labeled, and have energies consistent with the $\mathrm{Cs} \mathrm{PbBr}_{3}$ perovskite $\mathrm{QDs}^{70}$. In addition, the spectra show no different signals between $\mathrm{CsPbBr}_{3}-\mathrm{OA}$ and $\mathrm{Cs}_{3} \mathrm{PbBr}_{3}-$ DA QDs. These XPS characterizations also echo our XRD results and HRTEM images, indicating that the synthesis of $\mathrm{CsPbBr}_{3}$ QDs with DA ligand modification is successful. The chemical bonds of the $\mathrm{Cs} \mathrm{PbBr}_{3}-\mathrm{OA}$ QDs and $\mathrm{CsPbBr}_{3}-\mathrm{DA}$ QDs surface were determined by transform infrared (FTIR) spectroscopies. Figure 2(e) shows the FTIR spectra of the $\mathrm{CsPbBr}_{3}-\mathrm{OA}$ QDs and $\mathrm{CsPbBr}$-DA QDs. It is well known that the FTIR spectra are dominated by the vibrational modes of bound and unbound ligand molecules in the QDs surfaces. The peaks of $2921 \mathrm{~cm}^{-1}$ revealed the resonances of hydrocarbon chains with methyl $\left(-\mathrm{CH}_{3}\right)$. The peaks at $706 \mathrm{~cm}^{-1}$ are characteristic peaks of $-\left(\mathrm{CH}_{2}\right)_{\mathrm{n}}$ - in long chain saturated hydrocarbons. In particular, the peaks show the typical $\mathrm{C}-\mathrm{O}$ stretched and $\mathrm{C}-\mathrm{O}$ bends, indicating the existence of the acid ligand on the QD surface. The peak centered at $1462 \mathrm{~cm}^{-1}$ is attributed to stretching vibrations of DA group and OA group, indicating that the OA and DA ligands were both well capped on $\mathrm{CsPbBr}_{3}$ QDs after purification. To gain further insight into the differences between the DA and OA ligands, we characterized the two samples by quantitative $1 \mathrm{H}$ nuclear magnetic 


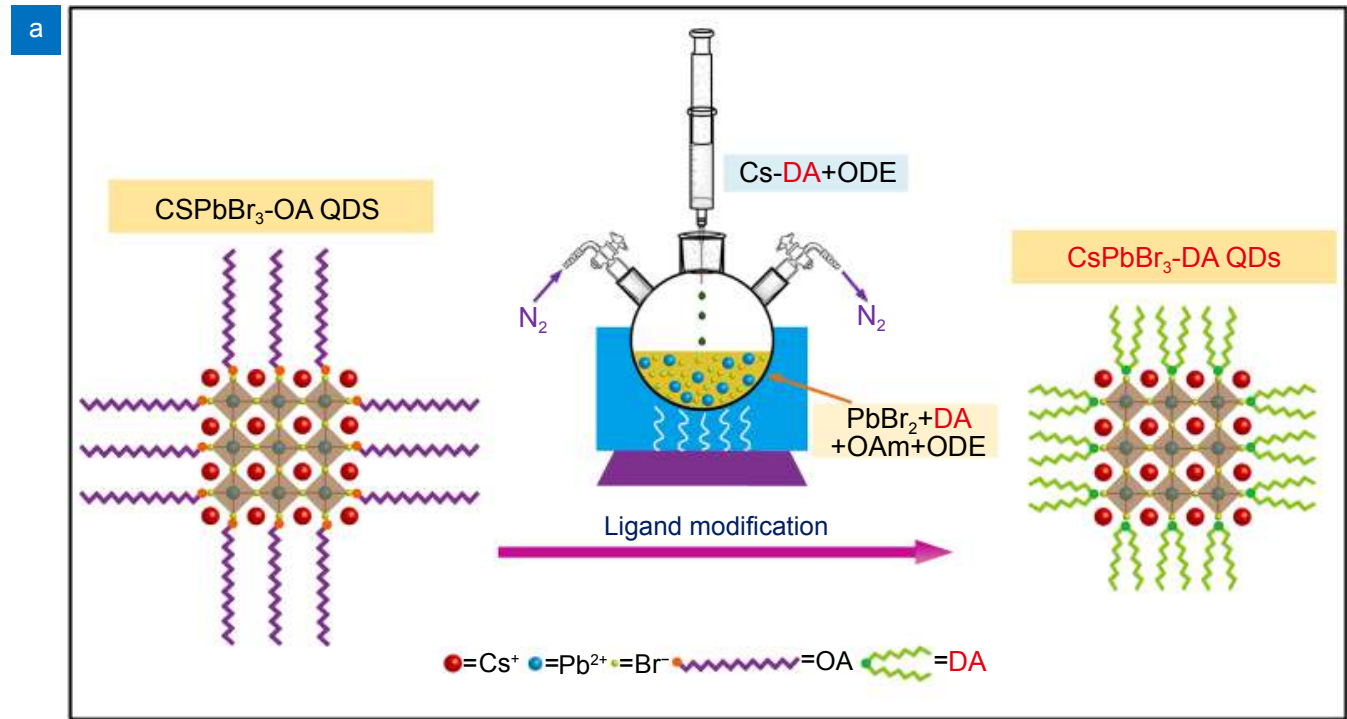

b
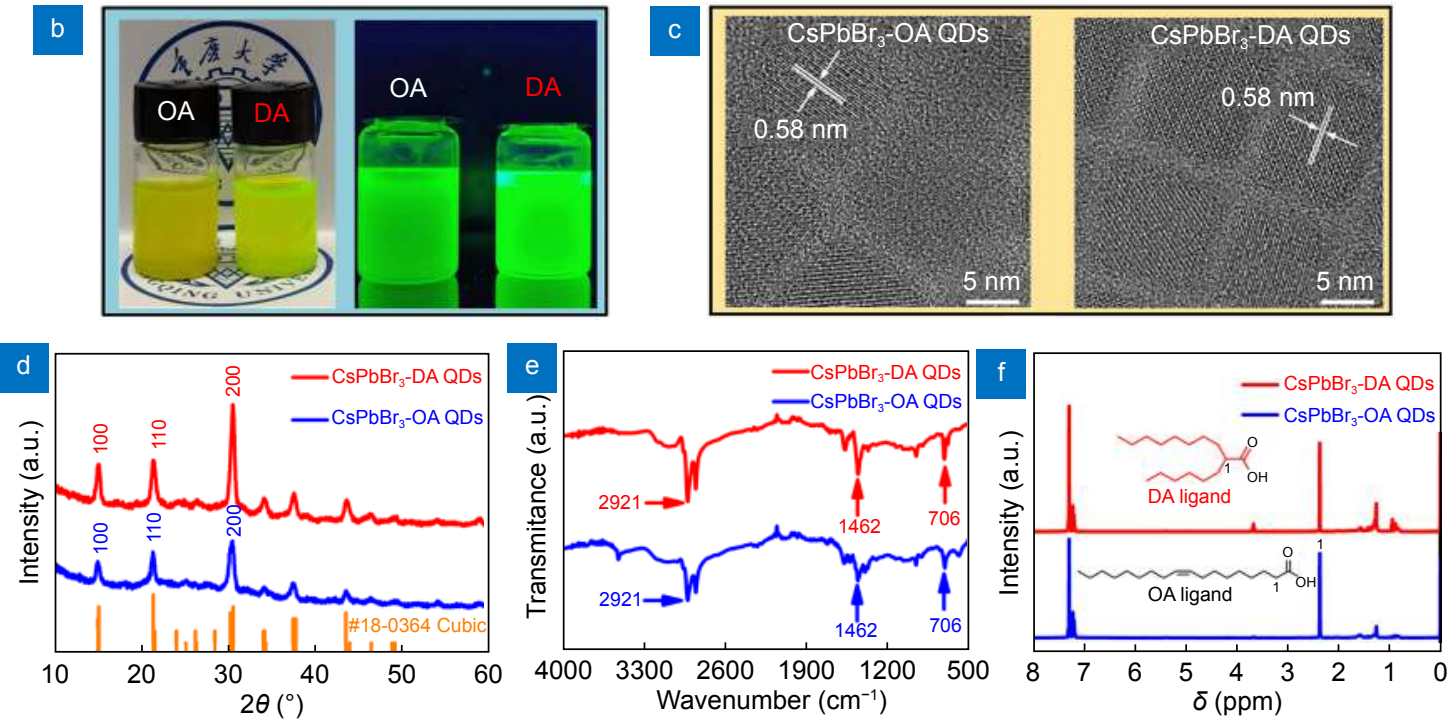

Fig. 2 | (a) The schematic illustration of the surface in the $\mathrm{CsPbBr}_{3}$ QDs with ligand modification process. (b) Photographs of the $\mathrm{CsPbBr}_{3} \mathrm{QDs}$ solution under the daylight (left) and UV light of $365 \mathrm{~nm}$ (right). (c) HRTEM images. (d) XRD patterns. (e) FTIR spectra. (f) ${ }^{1} \mathrm{H}-\mathrm{NMR}$ spectra after washed twice.

resonance (NMR) spectroscopy. The representative $1 \mathrm{H}$ NMR spectrum of both purified $\mathrm{CsPbBr}_{3}$ QDs solution is given in Fig. 2(f). We focus specifically on the signal region $(\delta=2-3 \mathrm{ppm})$ of the $1 \mathrm{H}$ NMR spectrum, which allows for analysis of acid ligand (OA or DA ligand) binding on the QDs surface ${ }^{71}$. Just like $\mathrm{CsPBr}_{3}-\mathrm{OA}$ QDs, it is obvious that a $\mathrm{H}$ peak from $-\mathrm{COOH}$ group is observed in $\mathrm{CsPbr}_{3}$-DA QDs, implying that DA ligand was bound to QDs surface. Hence, the DA ligand could bind to the QDs surface tightly and cap the QDs well.

In Fig. (3), we show the PL emission spectra and the $\mathrm{UV}$-vis absorption for both $\mathrm{CsPbBr}_{3}$ QD films with the same thickness of $500 \mathrm{~nm}$, which were measured under the same condition. We observe that the PL emission spectra in Fig. 3(a) are dominated by the emission peak at around $517 \mathrm{~nm}$, consistent with the previous reports ${ }^{72}$. As we expected, $\mathrm{CsPbBr}_{3}$-DA QD films exhibit a significantly enhanced PL intensity. In contrast to the PL spectra, we observe a single absorption peak at $510 \mathrm{~nm}$, indicating a significant occurrence of the Stokes shift (as shown in Fig. $3 b)^{73}$. It has been demonstrated that this shift is intrinsic to the QDs electronic structure. Additionally, the $\mathrm{PL}$ decays of both $\mathrm{CsPbr}_{3}$ QDs have been recorded in Fig. 3(c). Both of the two curves can be fitted with biexponential decay, the fitted parameters are shown in the inset table of Fig. 3(c), including the fastdecay component (radiative recombination lifetimes, $\tau_{\mathrm{r}}$ ), a slow-decay component (nonradiative recombination 
lifetime, $\left.\tau_{\mathrm{nr}}\right)$ and the average lifetimes $\left(\tau_{\mathrm{avg}}\right)$. The two decay curves show that the $\mathrm{CsPbBr}_{3}-\mathrm{DA}$ QDs and $\mathrm{CsPbBr}_{3}$-OA QDs films have the $\tau_{\text {avg }}$ lifetimes of 26.4 and 19.5 ns, respectively. In comparison with $\mathrm{CsPbBr}_{3}-$ OA QDs films, the longer lifetime of $\mathrm{CsPbBr}_{3}$-DA QDs films likely caused by the surface defect passivation and high crystallinity in the presence of DA ligands. Therefore, the ligand replacement from OA to DA can facilitate the optical performance improvement of $\mathrm{CsPbBr}_{3}$ QDs, including the increasing decay lifetime and lower surface defect density. Considering the film quality plays an important role in governing the performance of perovskite WLEDs, we next characterized the morphology of $\mathrm{CsPbBr}_{3}$ QD films by the atomic force microscopy (AFM). We drop-coated the QDs solution on the glass substrate with the same thickness of the layer used for the following WLEDs. Interestingly, we find that the uniformity of $\mathrm{CsPbBr}_{3}$-DA QDs films is much better than that of $\mathrm{CsPbBr}_{3}-\mathrm{OA} \mathrm{QDs}$ films. The root mean square (RMS) roughness of $\mathrm{CsPbBr}_{3}$-OA QDs film is $12.71 \mathrm{~nm}$ (Fig. 3(d)). By contrast, the $\mathrm{CsPBr}_{3}$-DA QDs films show a much lower RMS value of $7.62 \mathrm{~nm}$ (Fig. 3(e)). It is expected that the DA ligands could passivate the surface defects and mitigate the agglomeration of the $\mathrm{CsPbBr}_{3}$ QDs, leading to the high quality films.

To further evaluate the stability of the synthesized $\mathrm{CsPBr}_{3}$ QDs, both $\mathrm{CsPbBr}_{3}$ QDs under the ethanol surrounding were explored. Fig. 4(a) shows the photographs of both $\mathrm{CsPbBr}_{3}$ QDs solution subjected to the ethanol surrounding under the daylight and UV light.
Both $\mathrm{CsPbBr}_{3}$ QDs solutions exhibit clarification and brightness at the beginning of the measurement. Obviously, the $\mathrm{CsPbBr}_{3}$-DA QDs solution is much brighter than that of the $\mathrm{CsPbBr}_{3}-\mathrm{OA}$ QDs solution (left in Fig. $4(\mathrm{a})$ ). When the equal amount of $0.5 \mathrm{~mL}$ ethanol is added, the $\mathrm{CsPBBr}_{3}-\mathrm{OA}$ QDs solution rapidly turns to deep yellow under the daylight and the fluorescence also becomes dim under UV light. By remaining them in the ethanol for $90 \mathrm{~min}$, the $\mathrm{Cs} \mathrm{PbBr}_{3}-\mathrm{OA}$ QDs solution has become a homogeneous yellow mixture under the daylight, which emit a dim green light under UV light. By contrast, the $\mathrm{CsPbBr}_{3}$-DA QDs solution can still remain green and clear and keep a higher luminescence brightness (right in Fig. 4(a)). Figure 4(b) and 4(c) show the PL evolution of the $\mathrm{CsPbBr}_{3}-\mathrm{OA}$ QDs and $\mathrm{Cs}_{3} \mathrm{PbBr}_{3}-\mathrm{DA}$ QDs after mixed with $0.5 \mathrm{~mL}$ ethanol under the same measurement, respectively. As shown in Fig. 4(b), the PL intensity of $\mathrm{CsPbBr}_{3}-\mathrm{OA}$ QDs exhibits a severe decrease with the time increasing. In contrast, the $\mathrm{CsPbBr}_{3}-\mathrm{DA}$ QDs still maintained their 66\% of initial PL intensity even in the ethanol for 90 min (see Fig. 4(c)), indicating its stronger polar solvent resistance. Figure 4(d) provides a straight view on the degradation tendency of PL intensity, in which the stability of $\mathrm{CsPbBr}_{3}-\mathrm{DA}$ QDs is much better than that of $\mathrm{CsPbBr}_{3}-\mathrm{OA}$ QDs under the ethanol surrounding. In addition, the emission wavelength of the $\mathrm{Cs} \mathrm{PbBr}_{3}-\mathrm{OA}$ QDs gradually performed a red shift with the time increase, indicating the structural degradation and aggregation with ligands loss in ethanol conditions. In contrast, the emission wavelength of the $\mathrm{CsPbBr}_{3}-\mathrm{DA}$
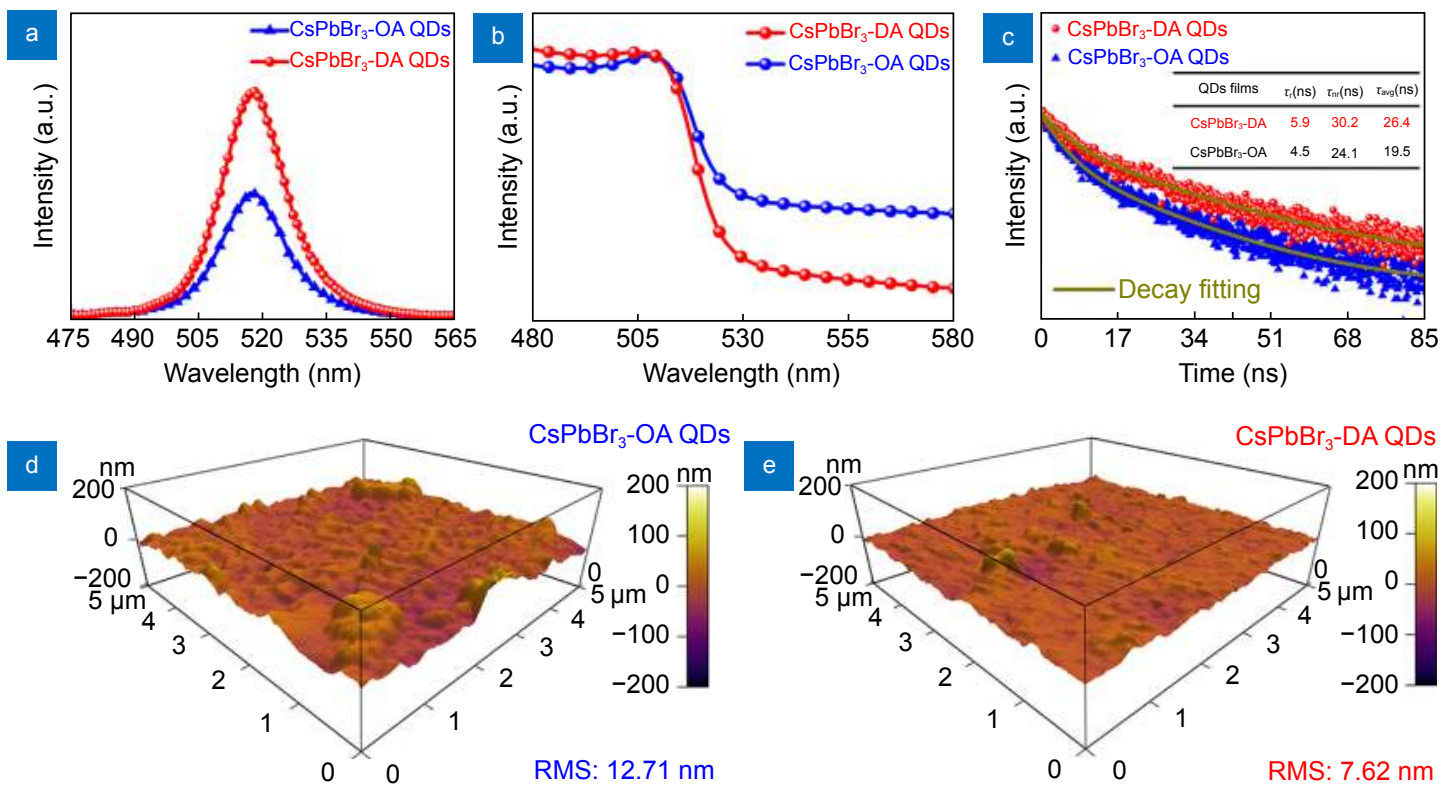

Fig. 3 | (a) PL spectra. (b) Absorption spectra. (c) PL decays and (d, e) AFM images of the QDs films. 

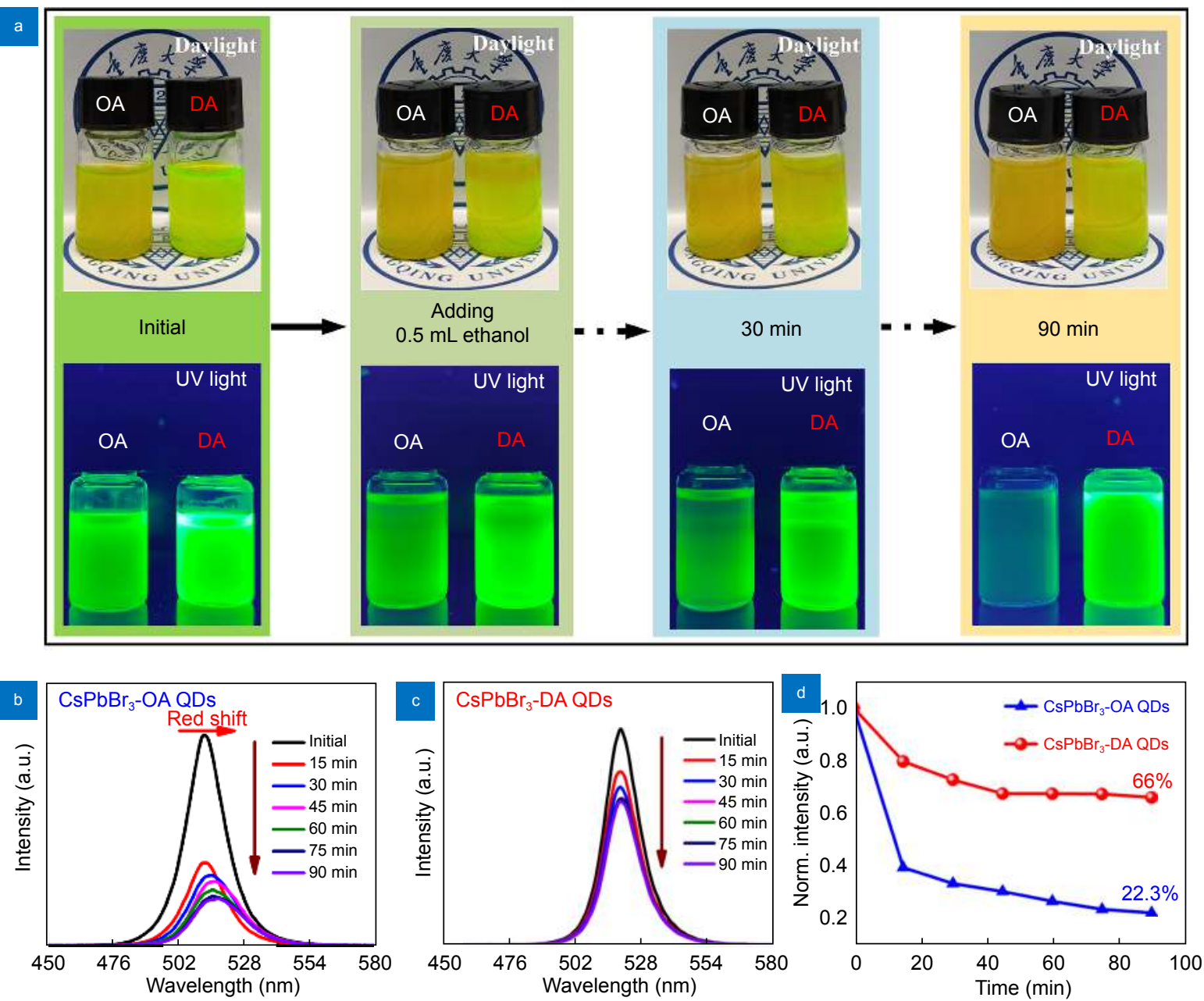

Fig. 4 | CsPbBr 3 -OA QDs and $\mathrm{CsPbBr}_{3}-\mathrm{DA}$ QDs in ethanol. (a) Photographs. (b, c) PL spectra. (d) PL intensity variation of QDs solutions over 90 min.

QDs has no shift. It is evident that the DA ligand could enhance the stability of $\mathrm{CsPBr}_{3}$ QDs, which should be due to the strong interaction between QDs and DA ligands ${ }^{74}$.

To gain more insight into the stability of the DA ligand modified $\mathrm{CsPbr}_{3}$ QDs, we explore the water stability on both $\mathrm{CsPBr}_{3}$ QD solution. The equivalent amount of both solid $\mathrm{CsPbr}_{3}$ QDs were dispersed in the $1.5 \mathrm{~mL}$ toluene to obtain the clear solution. The above solutions were added into the $2 \mathrm{~mL}$ ultrapure water. Figure 5 shows both $\mathrm{CsPbBr}_{3}$ QD solutions subjected to the ultrapure water under daylight and UV light. The color of $\mathrm{CsPbBr}_{3}-\mathrm{OA} \mathrm{QDs}$ solution changes from clear and green to colorlessness with the time increase under daylight and UV light, respectively, indicating that the $\mathrm{CsPb}$ $\mathrm{Br}_{3}$ perovskite structure is destroyed. Impressively, the green luminescence of the $\mathrm{CsPBr}_{3}$-DA QDs solution still retain even after 7 days and maintain the PLQY of 75.2\%. Therefore, it can be concluded that DA ligand modification is indeed beneficial to greatly improve the stability of $\mathrm{CsPbr}_{3}$ QDs and significantly suppress the degradation.

As discussed above, we have obtained green $\mathrm{CsPbBr}_{3}-$ DA QDs with high-quality and excellent stability. In order to fabricate the WLEDs, AgInZnS QDs were chosen to act as the red emission. The photographs, XRD pattern, absorption and PL emission spectra of the red AgInZnS QDs are shown in Fig. S5, respectively. Figure S5(a) presents the photograph of AgInZnS QD solution under the daylight and UV light. Fig. S5(b) shows the XRD patterns of AgInZnS QDs.

Obviously, the XRD patterns of the samples match well with that of standard phase crystal structure, and there is no impure peak. Figure S5(c) describes the absorption of the AgInZnS QDs. Figure S5(d) shows the red PL emission of AgInZnS QDs with centered emission peak at $610 \mathrm{~nm}$, which agrees well with the previous published work ${ }^{57}$. XPS is further applied to characterize 


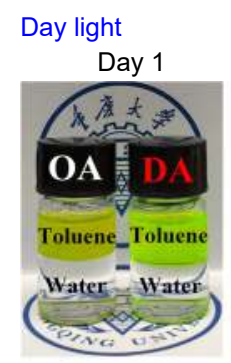

UV light

Day 1

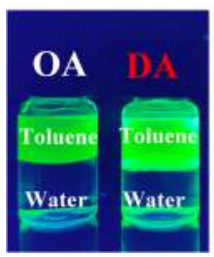

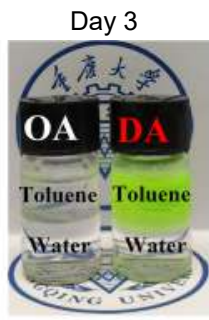

Day 3

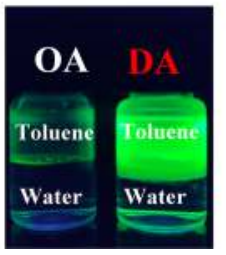

Day 5

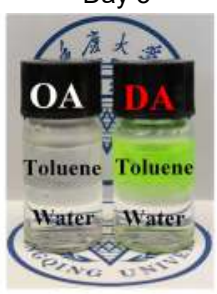

Day 5

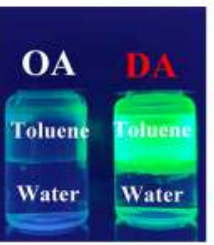

Day 7

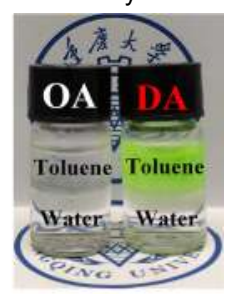

Day 7

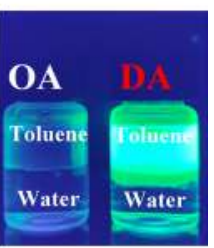

Fig. 5 | Photographs of $\mathrm{CsPbBr}_{3}$ QDs solution under daylight and UV light of $365 \mathrm{~nm}$.

the crystals of the synthesized samples. Figures S6 and S7 present the XPS spectra for a survey scan of the samples with all peaks (including $\mathrm{Ag} 3 \mathrm{~d}$, In $3 \mathrm{~d}, \mathrm{Zn} 2 \mathrm{p}$ and S 2p) labeled. Those results indicate that we have successfully synthesized the AgInZnS QDs.

To investigate the performance of WLEDs based on $\mathrm{CsPbBr}_{3}$ QDs, we combined green emitting $\mathrm{CsPbBr}_{3}$ QDs and red emitting AgInZnS QDs on the blue emitting InGaN chips. Figure 6(a) and 6(b) illustrate the EL spectra of $\mathrm{CsPbBr}_{3}-\mathrm{OA}$ QDs WLEDs and $\mathrm{CsPbBr}_{3}-\mathrm{DA}$ QDs WLEDs at a driving voltages of $2.65 \mathrm{~V}$, respectively.
Three emission peaks at 450, 520 and $610 \mathrm{~nm}$ have been observed, which are related to blue InGaN chip, $\mathrm{CsPbBr}_{3}$ QDs and AgInZnS QDs, respectively. The CIE color coordinates of $(0.32,0.35)$ and $(0.44,0.42)$ corresponding to the $\mathrm{CsPbBr}_{3}-\mathrm{OA}$ QDs and $\mathrm{CsPbBr}_{3}$-DA QDs WLEDs, respectively, as shown in Fig. 6(c).

As shown in Table 1, the characteristics of the fabricated WLEDs have been recorded, including CRI, CCT and CIE coordinates. The CCT (3018 K) of $\mathrm{CsPbBr}_{3}$-DA QDs WLEDs is lower than that of $\mathrm{CsPbBr}_{3}-\mathrm{OA}$ QDs WLEDs (6094 K). Notably, the CRI (93) and power
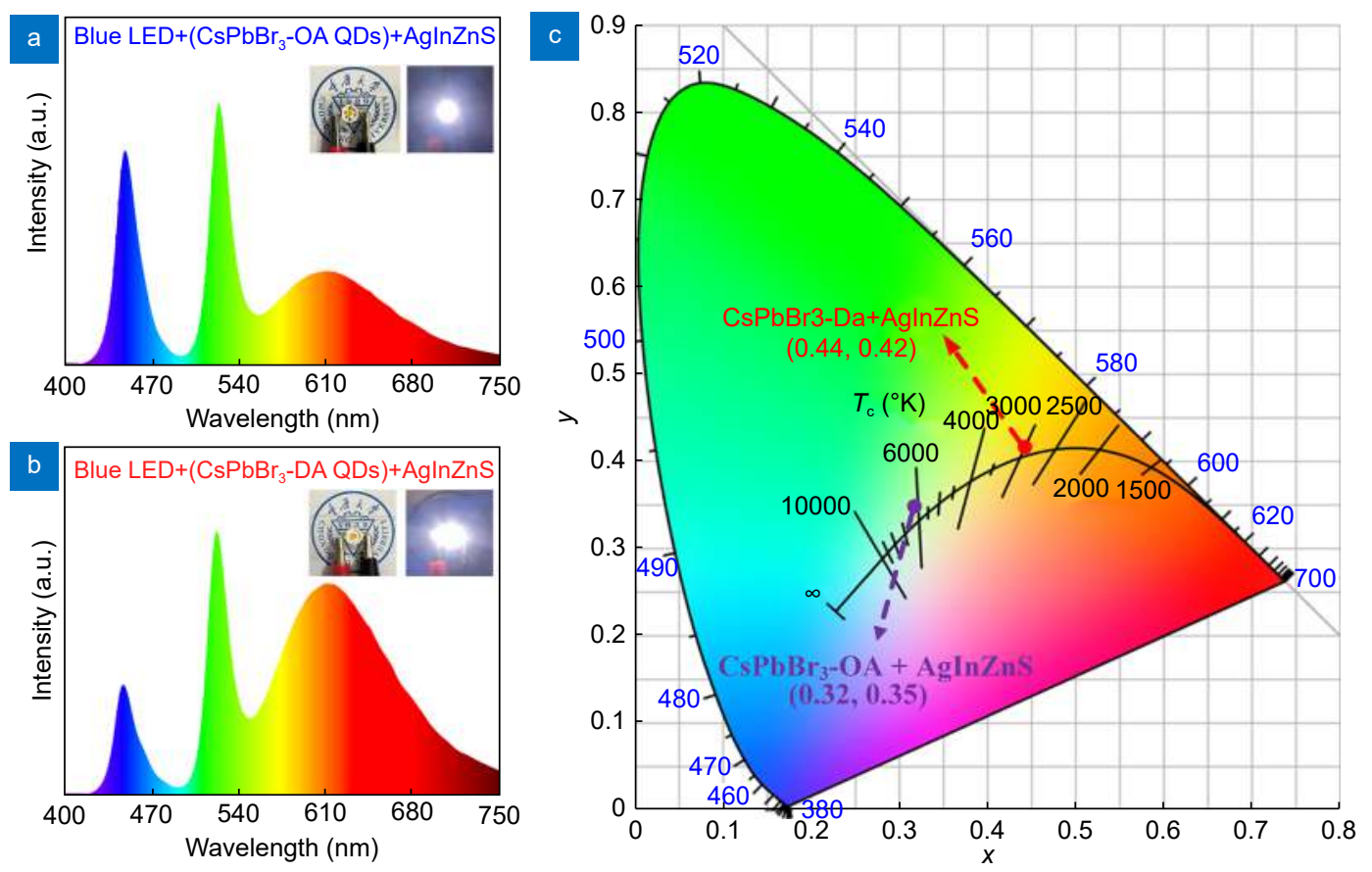

Fig. 6 | (a) PL spectrum of WLEDs based on $\mathrm{CsPbBr}_{3}-\mathrm{OA}$ QDs with a CRI of 82. (b) PL spectrum of WLEDs based on CsPbBr3-DA QDs with a CRI of 93 (The inset shows photographs of the devices without and with driving voltage). (c) CIE chromaticity diagram of both WLEDs. 
efficiency $(64.8 \mathrm{~lm} / \mathrm{W})$ of $\mathrm{CsPBBr}_{3}-\mathrm{DA}$ QDs WLEDs are much higher than those of $\mathrm{CsPbBr}_{3}-\mathrm{OA}$ QDs WLEDs (82 and $40.2 \mathrm{~lm} / \mathrm{W}$ ). It is evident that the $\mathrm{CsPbBr}_{3}-\mathrm{DA}$ QDs WLEDs exhibit better performance, which is attributed to the improved optical performance of the DA ligand modified $\mathrm{CsPbBr}_{3}$ QDs.

In Figs. S8 and S9, we have explored the behaviors of WLEDs with the increases of driving voltage. As the driving voltage increases from 2.5 to $2.62 \mathrm{~V}$, the greento-blue intensity ratio decreased by $45.1 \%$ for the $\mathrm{CsPb}$ $\mathrm{Br}_{3}$-OA QDs WLEDs, while it decreases by only $29 \%$ for the $\mathrm{CsPbBr}_{3}$-DA QDs WLEDs (see Fig. S10). Comparing $2.5 \mathrm{~V}$ to an even higher operating voltage of $2.8 \mathrm{~V}$, the decrease is $75.1 \%$ using the $\mathrm{CsPbBr}_{3}-\mathrm{OA}$ QDs and 65.1\% using the $\mathrm{CsPbr}_{3}$-DA QDs, implying that $\mathrm{CsPb}$ $\mathrm{Br}_{3}$-DA QDs demonstrate no obvious degradation. Figs. S8(b), S9(b), Tables S2 and S3 show the color coordinates and CCT/CRI of WLEDs with the increase of driving voltages. To evaluate the performance of the prepared WLEDs, we focus on the main optical parameters of WLEDs using $\mathrm{CsPbBr}_{3}$ QDs on the blue chip, see Table 2 for details. Obviously, the CRI of warm WLEDs here shows the highest value than those of published reports. We conclude from our results (in Figs. S8, S9, and Tables S2, S3, 2) that the degradation of $\mathrm{CsPbBr}_{3}-\mathrm{DA}$ QDs is less than that for $\mathrm{CsPbr}_{3}$-OA QDs under strong illumination. This suggests that ligand modified $\mathrm{CsPbBr}_{3}$-DA QDs have advantages over common $\mathrm{CsPb}$ $\mathrm{Br}_{3} \mathrm{QDs}$ for green emitting application.

The thermal imaging photographs of the prepared
WLEDs were measured under the different driven currents of $10 \mathrm{~mA}, 30 \mathrm{~mA}$ and $70 \mathrm{~mA}$, as shown in Fig. 7 . There is obvious temperature difference between $\mathrm{CsPb}$ $\mathrm{Br}_{3}-\mathrm{OA}$ QDs and $\mathrm{CsPbBr}_{3}-\mathrm{DA}$ QDs WLEDs at $10 \mathrm{~mA}$ driving current (see left insets in Fig. 7(a) and 7(b)). When driving current increases to $30 \mathrm{~mA}$, the temperature of $\mathrm{CsPbBr}_{3}-\mathrm{OA}$ QDs WLEDs is $23.6{ }^{\circ} \mathrm{C}$, while the $\mathrm{CsPbBr}$-DA QDs WLEDs exhibits a lower temperature of $21.2{ }^{\circ} \mathrm{C}$ (middle insets in Fig. 7(a) and 7(b)), i.e., the temperature of $\mathrm{CsPbBr}_{3}$-DA WLEDs is decreased by 2.4 ${ }^{\circ} \mathrm{C}$ under the same measurement condition. Notably, the right insets in Fig. 7(a) and 7(b) show the thermal imaging photographs $\mathrm{CsPbBr}_{3}-\mathrm{OA}$ QDs WLEDs with the temperature of $35.2{ }^{\circ} \mathrm{C}$ and $\mathrm{CsPbBr}_{3}$-DA QDs WLEDs with the temperature of $27^{\circ} \mathrm{C}$ under the same driving current of $70 \mathrm{~mA}$, respectively. In comparison with $\mathrm{CsPbBr}_{3}-\mathrm{OA}$ QDs WLEDs, the temperature of $\mathrm{CsPbBr}_{3}-$ DA QDs WLEDs decreases by $8.2^{\circ} \mathrm{C}$. We can conclude that the thermal imaging photographs indicate that the $\mathrm{CsPbBr}_{3}$-DA QDs WLEDs exhibit better thermal performance than that of the $\mathrm{CsPbBr}_{3}-\mathrm{OA}$ QDs WLEDs. Two factors account for the decreasing temperature of the $\mathrm{CsPbBr}_{3}$-DA QDs WLEDs. For $\mathrm{CsPbBr}_{3}-\mathrm{OA}$ QDs, the nonradiation emission is much more serious than that of $\mathrm{CsPbBr}_{3}$-DA QDs, which was confirmed by their lifetime decay, as described above in Fig. 3(c). The second factor is the lower radiative efficiency of $\mathrm{Cs} \mathrm{PbBr}_{3}-\mathrm{OA}$ QDs, which means that some photoexcited electrons can recombine with holes nonradiatively through thermal emission. The measured PLQY of

Table 1 | Optical parameters of WLEDs based on $\mathrm{CsPbBr}_{3}$ QDs.

\begin{tabular}{c|c|c|c|c|}
\hline Groups & CRI & CCT $(\mathrm{K})$ & Efficiency $(\operatorname{Im} / \mathrm{W})$ & CIE coordinates $(X, Y)$ \\
\hline $\mathrm{CsPbBr}_{3}-\mathrm{OA}+\mathrm{Ag} \operatorname{lnZnS}$ & 82 & 6094 & 40.2 & $(0.32,0.35)$ \\
$\mathrm{CsPbBr}_{3}-\mathrm{DA}+\mathrm{AgInZnS}$ & 93 & 3018 & 64.8 & $(0.44,0.42)$ \\
\hline
\end{tabular}

Table 2 | Comparison of the main optical parameters in WLEDs based on $\mathrm{CsPbBr}_{3}$ QDs.

\begin{tabular}{|c|c|c|c|c|}
\hline Color-converting materials & Power efficiency (Im/W) & CRI & $\mathrm{CCT}(\mathrm{K})$ & References \\
\hline $\mathrm{CsPbBr}_{3}+\mathrm{Sr}_{2} \mathrm{Si}_{5} \mathrm{~N}_{8}: \mathrm{Eu}^{2+}$ phosphors & 65.78 & 67.93 & 7540 & ref. $^{30}$ \\
\hline $\mathrm{CsPbBr}_{3}: \mathrm{Na}+\mathrm{K}_{2} \mathrm{SiF}_{6}: \mathrm{Mn}^{4+}(\mathrm{KSF})$ phosphors & 67.3 & 75.2 & 6652 & ref. ${ }^{33}$ \\
\hline $\mathrm{CsPbBr} / \mathrm{ZrO}_{2}+$ red phosphors & 64 & - & 4743 & ref. $^{75}$ \\
\hline $\mathrm{CsPbBr}_{3} / \mathrm{Cs}_{2} \mathrm{GeF}_{6}: \mathrm{Mn}^{4+}$ & 27.3 & 81.4 & - & ref. ${ }^{76}$ \\
\hline $\mathrm{CsPbBr}_{3}: \mathrm{Sn}+\mathrm{CaAlSiN}{ }_{3}: \mathrm{Eu}^{2+}$ phosphor & 29.06 & 74.2 & 3128 & ref. $^{77}$ \\
\hline $\mathrm{CsPb}\left(\mathrm{Br}_{1-x} \mathrm{I}_{x}\right)_{3}$ YAG:Ce & 19.0 & 84.7 & 3328 & ref. ${ }^{78}$ \\
\hline $\mathrm{CsPbBr}_{3} \mathrm{QD}$ glass + $\mathrm{CaAlSiN}_{3}: \mathrm{Eu}^{2+}$ & 50.5 & 83.4 & 3674 & ref. $^{79}$ \\
\hline $\mathrm{CsPbBr} / \mathrm{TDPA}+\mathrm{K}_{2} \mathrm{SiF}_{6}: \mathrm{Mn}^{4+}$ & 63 & 83 & 7072 & ref. ${ }^{80}$ \\
\hline $\mathrm{CsPbBr} / \mathrm{SiO}_{2}+\mathrm{CsPbBr}_{1.2} \mathrm{l}_{1.8}$ & 35.4 & - & 5623 & ref. ${ }^{81}$ \\
\hline Ligand modified $\mathrm{CsPbBr}_{3}+\mathrm{AglnZnS}$ & 64.8 & 93 & 3018 & This work \\
\hline
\end{tabular}




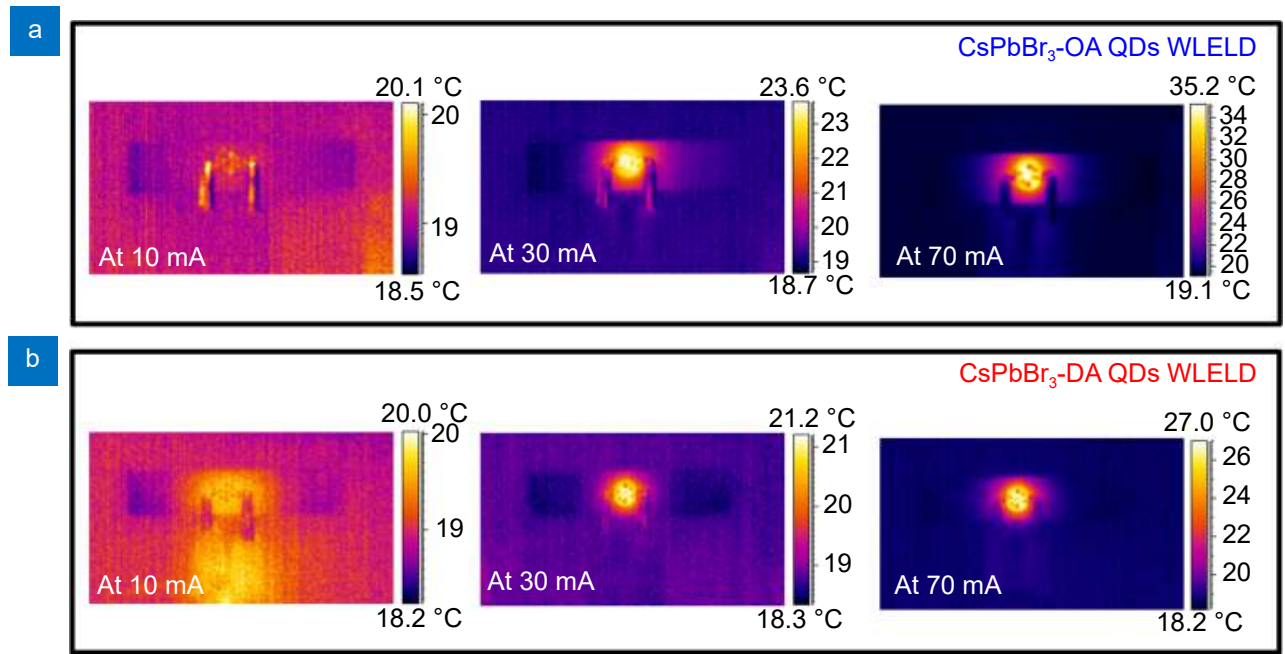

Fig. 7 | The thermal imaging photographs of (a) $\mathrm{CsPbBr}_{3}-\mathrm{OA}$ QDs WLEDs and (b) $\mathrm{CsPbBr}_{3}-\mathrm{DA}$ QDs WLEDs with various driving current.

$\mathrm{CsPbr}_{3}$-OA QDs is only $84 \%$, while the PLQY of $\mathrm{CsPb}$ $\mathrm{Br}_{3}$-DA QDs is $96 \%$. Therefore, there is an obviously increased non-radiative loss in the $\mathrm{CsPbBr}_{3}$-OA QDs, resulting in a high temperature in WLEDs.

\section{Conclusions}

In summary, we successfully synthesized high performance and excellent stability of $\mathrm{CsPbr}_{3}$ QDs by ligand modification. Compared with the regular $\mathrm{CsPbBr}_{3}$ QDs, a substantially improved stability of ligand modified $\mathrm{CsPbBr}_{3}$ QDs against ethanol and water was achieved. Further, the fabricated WLEDs by combining ligand modified $\mathrm{CsPbBr}_{3}$ QDs with red AgInZnS QDs on InGaN blue chips exhibit the excellent luminescent performance, including color coordinate of $(0.44,0.42)$, high color rendering index (CRI) of 93 and power efficiency of $64.8 \mathrm{~lm} / \mathrm{W}$. Moreover, the WLEDs based on the ligand modified $\mathrm{CsPbBr}_{3}$ QDs under high driving current demonstrate the better thermal performance than that of WLEDs using regular $\mathrm{CsPbBr}_{3}$ QDs. The excellent performances of WLEDs and facile approach used here will enrich the application of ligand modified $\mathrm{CsPb}$ $\mathrm{Br}_{3}$ QDs and demonstrate an effective way to prepare effective WLEDs.

\section{References}

1. Sun YR, Giebink NC, Kanno H, Ma BW, Thompson ME et al. Management of singlet and triplet excitons for efficient white organic light-emitting devices. Nature 440, 908-912 (2006).

2. Schreuder MA, Xiao K, Ivanov IN, Weiss SM, Rosenthal SJ. White light-emitting diodes based on Ultrasmall CdSe nanocrystal electroluminescence. Nano Lett 10, 573-576 (2010).

3. Crawford MH. LEDs for solid-state lighting: performance chal- lenges and recent advances. IEEE J Sel Top Quantum Electron 15, 1028-1040 (2009).

4. McKittrick J, Shea-Rohwer LE. Review: down conversion materials for solid-state lighting. J Am Ceram Soc 97, 1327-1352 (2014).

5. Schubert EF, Kim JK. Solid-state light sources getting smart. Science 308, 1274-1278 (2005).

6. Carlos LD, Ferreira RAS, de Zea Bermudez V, Julián-López B, Escribano P. Progress on lanthanide-based organic-inorganic hybrid phosphors. Chem Soc Rev 40, 536-549 (2011).

7. George NC, Denault KA, Seshadri R. Phosphors for solid-state white lighting. Annu Rev Mater Res 43, 481-501 (2013).

8. Huang $\mathrm{XY}$. Red phosphor converts white LEDs. Nat Photonics 8, 748-749 (2014).

9. Eliseeva SV, Bünzli JCG. Lanthanide luminescence for functional materials and bio-sciences. Chem Soc Rev 39, 189-227 (2010).

10. D'Andrade BW, Forrest SR. White organic light-emitting devices for solid-state lighting. Adv Mater 16, 1585-1595 (2004).

11. Protesescu L, Yakunin S, Bodnarchuk MI, Krieg F, Caputo R et al. Nanocrystals of cesium lead halide perovskites $\left(\mathrm{CsPbX}_{3}\right.$, $X=\mathrm{Cl}, \mathrm{Br}$, and $\mathrm{I}$ ): novel optoelectronic materials showing bright emission with wide color gamut. Nano Lett 15, 3692-3696 (2015).

12. Sutherland BR, Sargent EH. Perovskite photonic sources. Nat Photonics 10, 295-302 (2016).

13. Wang $Y$, Li XM, Song JZ, Xiao L, Zeng HB et al. All-inorganic colloidal perovskite quantum dots: a new class of lasing materials with favorable characteristics. Adv Mater 27, 7101-7108 (2015).

14. Sun SB, Yuan D, Xu Y, Wang AF, Deng ZT. Ligand-mediated synthesis of shape-controlled cesium lead halide perovskite nanocrystals via reprecipitation process at room temperature. ACS Nano 10, 3648-3657 (2016).

15. Nedelcu G, Protesescu L, Yakunin S, Bodnarchuk MI, Grotevent $\mathrm{MJ}$ et al. Fast anion-exchange in highly luminescent nanocrystals of cesium lead halide perovskites $\left(\mathrm{CsPbX}_{3}, X=\mathrm{Cl}\right.$, $\mathrm{Br}, \mathrm{I})$. Nano Lett 15, 5635-5640 (2015).

16. Zhang DD, Eaton SW, Yu Y, Dou LT, Yang PD. Solution-phase 
synthesis of cesium lead halide perovskite nanowires. J Am Chem Soc 137, 9230-9233 (2015).

17. Li CL, Zang ZG, Han C, Hu ZP, Tang XS et al. Highly compact $\mathrm{CsPbBr}_{3}$ perovskite thin films decorated by $\mathrm{ZnO}$ nanoparticles for enhanced random lasing. Nano Energy 40, 195-202 (2017).

18. Li CL, Zang ZG, Chen WW, Hu PZ, Tang XS et al. Highly pure green light emission of perovskite $\mathrm{CsPbBr}_{3}$ quantum dots and their application for green light-emitting diodes. Optics Express 24, 15071-15078 (2016).

19. Akkerman QA, D'Innocenzo V, Accornero S, Scarpellini A, Petrozza $A$ et al. Tuning the optical properties of cesium lead halide perovskite nanocrystals by anion exchange reactions. J Am Chem Soc 137, 10276-10281 (2015).

20. Song JZ, Li JH, Li XM, Xu LM, Dong YH et al. Quantum dot light-emitting diodes based on inorganic perovskite cesium lead halides ( $\left.\mathrm{CsPbX}_{3}\right)$. Adv Mater 27, 7162-7167 (2015).

21. Li JH, Xu LM, Wang T, Song JZ, Chen JW et al. 50-Fold EQE Improvement up to $6.27 \%$ of solution-processed all-inorganic perovskite $\mathrm{CsPbBr}_{3}$ QLEDs via surface ligand density control. Adv Mater 29, 1603885 (2017).

22. Ling $Y C$, Tian $Y$, Wang $X$, Wang JC, Knox JM et al. Enhanced optical and electrical properties of polymer-assisted all-inorganic perovskites for light-emitting diodes. Adv Mater 28, 8983-8989 (2016).

23. Bohn BJ, Tong $Y$, Gramlich M, Lai ML, Döblinger M et al. Boosting tunable blue luminescence of halide perovskite nanoplatelets through postsynthetic surface trap repair. Nano Lett 18, 5231-5238 (2018).

24. Song JZ, Li JH, Xu LM, Li JH, Zhang FJ et al. Room-temperature triple-ligand surface engineering synergistically boosts ink stability, recombination dynamics, and charge injection toward EQE-11.6\% perovskite QLEDs. Adv Mater 30, 1800764 (2018).

25. Lin KB, Xing J, Quan LN, de Arquer FPG, Gong XW et al. Perovskite light-emitting diodes with external quantum efficiency exceeding 20 per cent. Nature 562, 245-248 (2018).

26. Chiba $\mathrm{T}$, Hayashi $\mathrm{Y}$, Ebe $\mathrm{H}$, Hoshi $\mathrm{K}$, Sato $\mathrm{J}$ et al. Anion-exchange red perovskite quantum dots with ammonium iodine salts for highly efficient light-emitting devices. Nat Photonics 12, 681-687 (2018)

27. Vashishtha $P, \mathrm{Ng} \mathrm{M}$, Shivarudraiah SB, Halpert JE. High efficiency blue and green light-emitting diodes using ruddlesden-popper inorganic mixed halide perovskites with butylammonium interlayers. Chem Mater 31, 83-89 (2019).

28. Li ZC, Chen ZM, Yang YC, Xue QF, Yip HL et al. Modulation of recombination zone position for quasi-two-dimensional blue perovskite light-emitting diodes with efficiency exceeding $5 \%$. Nat Commun 10, 1027 (2019)

29. Cao Y, Wang NN, Tian H, Guo JS, Wei YQ et al. Perovskite light-emitting diodes based on spontaneously formed submicrometre-scale structures. Nature 562, 249-253 (2018).

30. Song $\mathrm{YH}$, Yoo JS, Kang BK, Choi SH, Ji EK et al. Long-term stable stacked $\mathrm{CsPbBr}_{3}$ quantum dot films for highly efficient white light generation in LEDs. Nanoscale 8, 19523-19526 (2016).

31. Ma KZ, Du XY, Zhang YW, Chen S. In situ fabrication of halide perovskite nanocrystals embedded in polymer composites via microfluidic spinning microreactors. J Mater Chem C $\mathbf{5}$,
9398-9404 (2017).

32. Kim Y, Yassitepe E, Voznyy O, Comin R, Walters $G$ et al. Efficient luminescence from perovskite quantum dot solids. ACS Appl Mater Interfaces 7, 25007-25013 (2015).

33. Li S, Shi ZF, Zhang F, Wang LT, Ma ZZ et al. Sodium dopingenhanced emission efficiency and stability of $\mathrm{CsPbBr}_{3}$ nanocrystals for white light-emitting devices. Chem Mater 31, 3917-3928 (2019).

34. Quarta D, Imran M, Capodilupo AL, Petralanda U, van Beek B et al. Stable ligand coordination at the surface of colloidal $\mathrm{CsPb}-$ $\mathrm{Br}_{3}$ nanocrystals. J Phys Chem Lett 10, 3715-3726 (2019).

35. Wang HR, Zhang $X Y, W u Q Q$, Cao F, Yang DW et al. Trifluoroacetate induced small-grained $\mathrm{CsPbBr}_{3}$ perovskite films result in efficient and stable light-emitting devices. Nat Commun 10, 665 (2019).

36. Imran M, ljaz P, Goldoni L, Maggioni D, Petralanda U et al. Simultaneous cationic and anionic ligand exchange for colloidally stable $\mathrm{CsPbBr}_{3}$ nanocrystals. ACS Energy Lett 4, 819-824 (2019).

37. Krieg F, Ochsenbein ST, Yakunin S, ten Brinck S, Aellen P et al. Colloidal $\mathrm{CsPbX}_{3}(X=\mathrm{Cl}, \mathrm{Br}, \mathrm{I})$ nanocrystals 2.0: zwitterionic capping ligands for improved durability and stability. ACS Energy Lett 3, 641-646 (2018).

38. Yuan X, Hou XM, Li J, Qu CQ, Zhang WJ et al. Thermal degradation of luminescence in inorganic perovskite $\mathrm{CsPbBr}_{3}$ nanocrystals. Phys Chem Chem Phys 19, 8934-8940 (2017).

39. Zhang M, Tian ZQ, Zhu DL, He H, Guo SW et al. Stable CsPb$\mathrm{Br}_{3}$ perovskite quantum dots with high fluorescence quantum yields. New J Chem 42, 9496-9500 (2018).

40. Liu PZ, Chen W, Wang WG, Xu B, Wu D et al. Halide-rich synthesized cesium lead bromide perovskite nanocrystals for lightemitting diodes with improved performance. Chem Mater 29, 5168-5173 (2017).

41. Dutta A, Dutta SK, Das Adhikari S, Pradhan N. Phase-stable $\mathrm{CsPbl}_{3}$ nanocrystals: the reaction temperature matters. Angew Chem Int Ed 57, 9083-9087 (2018).

42. Imran M, Caligiuri V, Wang MJ, Goldoni L, Prato M et al. Benzoyl halides as alternative precursors for the colloidal synthesis of lead-based halide perovskite nanocrystals. J Am Chem Soc 140, 2656-2664 (2018).

43. Liu F, Ding C, Zhang YH, Ripolles TS, Kamisaka T et al. Colloidal synthesis of air-stable alloyed $\mathrm{CsSn}_{1-x} \mathrm{~Pb}_{x} \mathrm{I}_{3}$ perovskite nanocrystals for use in solar cells. J Am Chem Soc 139, 16708-16719 (2017).

44. Guria AK, Dutta SK, Adhikari SD, Pradhan N. Doping $\mathrm{Mn}^{2+}$ in lead halide perovskite nanocrystals: successes and challenges. ACS Energy Lett 2, 1014-1021 (2017).

45. Pan J, Shang YQ, Yin J, De Bastiani M, Peng W et al. Bidentate ligand-passivated $\mathrm{CsPbl}_{3}$ perovskite nanocrystals for stable near-unity photoluminescence quantum yield and efficient red light-emitting diodes. J Am Chem Soc 140, 562-565 (2018).

46. Almeida G, Infante I, Manna L. Resurfacing halide perovskite nanocrystals. Science 364, 833-834 (2019).

47. Zhang BW, Goldoni L, Zito J, Dang ZY, Almeida G et al. Alkyl phosphonic acids deliver $\mathrm{CsPbBr}_{3}$ nanocrystals with high photoluminescence quantum yield and truncated octahedron shape. Chem Mater 31, 9140-9147 (2019). 
48. Li Y, Lv Y, Guo ZQ, Dong LB, Zheng JH et al. One-step preparation of long-term stable and flexible $\mathrm{CsPbBr}_{3}$ perovskite quantum dots/ethylene vinyl acetate copolymer composite films for white light-emitting diodes. ACS Appl Mater Interfaces 10, 15888-15894 (2018).

49. Song YH, Park SY, Yoo JS, Park WK, Kim HS et al. Efficient and stable green-emitting $\mathrm{CsPbBr}_{3}$ perovskite nanocrystals in a microcapsule for light emitting diodes. Chem Eng J 352, 957-963 (2018).

50. Le TH, Choi Y, Kim S, Lee U, Heo E et al. Highly elastic and $>200 \%$ reversibly stretchable down-conversion white light-emitting diodes based on quantum dot gel emitters. Adv Opt Mater 8, 1901972 (2020).

51. Chen M, Hu HC, Tan YS, Yao N, Zhong QX et al. Controlled growth of dodecapod-branched $\mathrm{CsPbBr}_{3}$ nanocrystals and their application in white light emitting diodes. Nano Energy 53, 559-566 (2018).

52. Chang YJ, Yoon YJ, Li GP, Xu EZ, Yu ST et al. All-inorganic perovskite nanocrystals with a stellar set of stabilities and their use in white light-emitting diodes. ACS Appl Mater Interfaces 10, 37267-37276 (2018).

53. Guner T, Demir MM. A review on halide perovskites as color conversion layers in white light emitting diode applications. Phys Status Solidi (A) 215, 1800120 (2018).

54. Hu YQ, Bai F, Liu XB, Ji QM, Miao XL et al. Bismuth incorporation stabilized $\alpha-\mathrm{CsPbl}_{3}$ for fully inorganic perovskite solar cells. ACS Energy Lett 2, 2219-2227 (2017).

55. Sanehira EM, Marshall AR, Christians JA, Harvey SP, Ciesielski $\mathrm{PN}$ et al. Enhanced MOBILITY $\mathrm{CsPbl}_{3}$ quantum dot arrays for record-efficiency, high-voltage photovoltaic cells. Sci Adv 3, eaao4204 (2017).

56. Liu F, Zhang YH, Ding C, Kobayashi S, Izuishi T et al. Highly luminescent phase-stable $\mathrm{CsPbl}_{3}$ perovskite quantum dots achieving near $100 \%$ absolute photoluminescence quantum yield. ACS Nano 11, 10373-10383 (2017).

57. Zang ZG, Zeng XF, Wang M, Hu W, Liu CR et al. Tunable photoluminescence of water-soluble AglnZnS-graphene oxide (GO) nanocomposites and their application in-vivo bioimaging. Sens Actuators B-Chem 252, 1179-1186 (2017).

58. Yang ZQ, Chen WW, Zu ZQ, Zang ZG, Yang YC et al. Facile synthesis and photoluminescence characterization of AglnZnS hollow nanoparticles. Mater Lett 151, 89-92 (2015).

59. Blum V, Gehrke R, Hanke F, Havu P, Havu V et al. Ab initio molecular simulations with numeric atom-centered orbitals. Comput Phys Commun 180, 2175-2196 (2009).

60. Perdew JP, Burke K, Ernzerhof M. Generalized gradient approximation made simple. Phys Rev Lett 77, 3865-3868 (1996).

61. Tkatchenko A, Scheffler M. Accurate molecular van der Waals interactions from ground-state electron density and free-atom reference data. Phys Rev Lett 102, 073005 (2009).

62. Yang DD, Li XM, Zhou WH, Zhang SL, Meng CF et al. $\mathrm{CsPbBr}_{3}$ Quantum Dots 2.0: benzenesulfonic acid equivalent ligand awakens complete purification. Adv Mater 31, 1900767 (2019).

63. Ravi VK, Santra PK, Joshi N, Chugh J, Singh SK et al. Origin of the substitution mechanism for the binding of organic ligands on the surface of $\mathrm{CsPbBr}_{3}$ perovskite nanocubes. J Phys Chem Lett 8, 4988-4994 (2017).
64. Xu WD, Hu Q, Bai S, Bao CX, Miao YF et al. Rational molecular passivation for high-performance perovskite light-emitting diodes. Nat Photonics 13, 418-424 (2019).

65. Gong MG, Sakidja R, Goul R, Ewing D, Casper M et al. Highperformance all-inorganic $\mathrm{CsPbCl}_{3}$ perovskite nanocrystal photodetectors with superior stability. ACS Nano 13, 1772-1783 (2019).

66. Law M, Luther JM, Song Q, Hughes BK, Perkins CL et al. Structural, optical, and electrical properties of PbSe nanocrystal solids treated thermally or with simple amines. J Am Chem Soc 130, 5974-5985 (2008).

67. Koleilat GI, Levina L, Shukla H, Myrskog SH, Hinds S et al. Efficient, stable infrared photovoltaics based on solution-cast colloidal quantum dots. ACS Nano 2, 833-840 (2008).

68. Beard MC, Midgett AG, Law M, Semonin OE, Ellingson RJ et al. Variations in the quantum efficiency of multiple exciton generation for a series of chemically treated PbSe nanocrystal films. Nano Lett 9, 836-845 (2009).

69. Tang J, Kemp KW, Hoogland S, Jeong KS, Liu H et al. Colloidal-quantum-dot photovoltaics using atomic-ligand passivation. Nat Mater 10, 765-771 (2011).

70. Liu M, Zhong GH, Yin YM, Miao JS, Li K et al. Aluminum-doped cesium lead bromide perovskite nanocrystals with stable blue photoluminescence used for display backlight. Adv Sci 4, 1700335 (2017).

71. Smock SR, Williams TJ, Brutchey RL. Quantifying the thermodynamics of ligand binding to $\mathrm{CsPbBr}_{3}$ quantum dots. Angew Chem Int Ed 57, 11711-11715 (2018).

72. Swarnkar A, Chulliyil R, Ravi VK, Irfanullah M, Chowdhury A et al. Colloidal $\mathrm{CsPbBr}_{3}$ perovskite nanocrystals: luminescence beyond traditional quantum dots. Angew Chem Int Ed 54, 15424-15428 (2015).

73. Brennan MC, Herr JE, Nguyen-Beck TS, Zinna J, Draguta S et al. Origin of the size-dependent stokes shift in $\mathrm{CsPbBr}_{3}$ perovskite nanocrystals. J Am Chem Soc 139, 12201-12208 (2017).

74. Yan DD, Shi TC, Zang ZG, Zhou TW, Liu ZZ et al. Ultrastable $\mathrm{CsPbBr}_{3}$ perovskite quantum dot and their enhanced amplified spontaneous emission by surface ligand modification. Small 15, 1901173 (2019).

75. Mo QH, Chen C, Cai WS, Zhao SY, Yan DD, Zang ZG. Room Temperature synthesis of stable zrconia- coated CsPbBr3 nanocrystals for white light - emitting diodes and visible light communication. Laser \& Photon. Rev. 15, 2100278 (2021).

76. Wei Y, Li K, Cheng ZY, Liu MM, Xiao H et al. Epitaxial growth of $\mathrm{CsPbX}_{3}(X=\mathrm{Cl}, \mathrm{Br}, \mathrm{I})$ perovskite quantum dots via surface chemical conversion of $\mathrm{Cs}_{2} \mathrm{GeF}_{6}$ double perovskites: a novel strategy for the formation of leadless hybrid perovskite phosphors with enhanced stability. Adv Mater 31, 1807592 (2019).

77. Liu SN, Shao GZ, Ding L, Liu JM, Xiang WD et al. Sn-doped $\mathrm{CsPbBr}_{3}$ QDs glasses with excellent stability and optical properties for WLED. Chem Eng J 361, 937-944 (2019).

78. Singh BP, Lin SY, Wang HC, Tang AC, Tong HC et al. Inorganic red perovskite quantum dot integrated blue chip: a promising candidate for high color-rendering in w-LEDs. RSC Adv 6, 79410-79414 (2016).

79. Di XX, Hu ZM, Jiang JT, He ML, Zhou L et al. Use of long-term 
stable $\mathrm{CsPbBr}_{3}$ perovskite quantum dots in phospho-silicate glass for highly efficient white LEDs. Chem Commun 53, 11068-11071 (2017).

80. Xuan TT, Yang XF, Lou SQ, Huang JJ, Liu Y et al. Highly stable $\mathrm{CsPbBr}_{3}$ quantum dots coated with alkyl phosphate for white light-emitting diodes. Nanoscale 9, 15286-15290 (2017).

81. Park DH, Han JS, Kim W, Jang HS. Facile synthesis of thermally stable $\mathrm{CsPbBr}_{3}$ perovskite quantum dot- inorganic $\mathrm{SiO}_{2}$ composites and their application to white light-emitting diodes with wide color gamut. Dyes Pigm 149, 246-252 (2018).

\section{Acknowledgements}

This work was financially supported by the National Natural Science Foundation of China (NSFC) (Grant Nos. 11974063, 11904156), and Postdoctoral Science Foundation of China (No. 2019M653336). The calcu- lations were done at the Center for Computational Science and Engineering of Southern University of Science and Technology (SUSTech).

\section{Author contributions}

Z. G. Zang conceived the idea. D. D. Yan conducted the experiments and wrote the manuscript. Y. B. zhang prepared the theoretical calculation. S. Y. Zhao and H. X. Wang were involved in the analysis of the results.

\section{Competing interests}

The authors declare no competing financial interests.

\section{Supplementary information}

Supplementary information for this paper is available at https://doi.org/10.29026/oea.2022.200075 